\title{
APLICAÇÃO DA TEORIA DA APRENDIZAGEM SIGNIFICATIVA NA ABORDAGEM DOS TEMAS CONTEMPORÂNEOS TRANSVERSAIS
}

\author{
Gisele Carvalho da Silva Nogueira ${ }^{1}$ \\ Carina Silva Rangel Dimas ${ }^{2}$
}

\begin{abstract}
RESUMO: O presente estudo surge da necessidade de investigação sobre a abordagem dos Temas Contemporâneos Transversais (TCT's), como prática educativa a fim de ativar conhecimentos subsunçores nos discentes, esses, oriundos da Teoria da Aprendizagem Significativa, desenvolvida pelo psicólogo David Paul Ausubel (25 de outubro de 1918 - 09 de julho de 2008). Com embasamento na pesquisa bibliográfica e documental constatou-se que a aplicação dos TCT's no âmbito educacional, faz com que o aluno consiga relacionar os conteúdos escolares com o seu meio social, de forma a colaborar para que os saberes sejam críticos e reflexivos. Nessa perspectiva a teoria da aprendizagem significativa deve estar atrelada aos TCT's de modo interdependente para que o docente ative os conhecimentos prévios do educando e paralelamente construa novos conhecimentos relacionando os TCT's aos conteúdos escolares.
\end{abstract}

Palavras-Chave: Temas contemporâneos transversais; Teoria da aprendizagem significativa; Construção do conhecimento; Conhecimentos subsunçores; Currículo.

\section{APPLICATION OF THE SIGNIFICANT LEARNING THEORY IN THE APPROACH OF CONTEMPORARY CROSS-SECTOR ISSUES}

\begin{abstract}
In this scientific essay, sought to approach the Contemporary Cross-cutting Themes (TCT's), as an educational practice in order to activate subsumptive knowledge in students, these, originating from the Theory of Meaningful Learning, developed by the psychologist David Paul Ausubel (October 25, 1918 - July 9, 2008). Based on bibliographic and documentary research, it was found that the application of TCT's in the educational field, makes the student able to relate school content with his social environment, in order to collaborate so that knowledge is critical and reflective. In this perspective, the theory of meaningful learning must be linked to the TCT's in an interdependent way so that the teacher activates the previous knowledge of the student and in parallel builds new knowledge relating the TCT's to the school contents.
\end{abstract}

Keywords: contemporary transversal themes; theory of meaningful learning; knowledge construction; subsunctional knowledge; curriculum.

\footnotetext{
${ }^{1}$ Instituto Federal Fluminense. E-mail: gcscn.iff@gmail.com

${ }^{2}$ Instituto Federal Fluminense. E-mail: carinarangeldimas@ gmail.com
} 


\section{INTRODUÇÃO}

No âmbito educacional, é perceptível que grande parte dos discentes ao realizar as atividades pedagógicas, reproduzem um processo de decodificação e memorização segmentado em cada disciplina, sem compreender como essas atividades impactam em seu meio social.

Este trabalho consiste em explorar como os Temas Contemporâneos Transversais (TCT's), provenientes da Base Nacional Comum Curricular - BNCC (2017) podem colaborar de maneira significativa com o processo de ensino e aprendizagem, estabelecendo uma vinculação entre a sociedade e os saberes escolares, ponderando acerca dos alicerces da Teoria da Aprendizagem, através da realização de pesquisa bibliográfica e documental.

A fragmentação dos conteúdos vem sendo dialogada ao percorrer de algumas décadas e a BNCC (2017) elucida que a prática educativa através dos TCT's cria possibilidades para que o educando e o educador exerçam a sua autonomia em sala de aula, colaborando assim, com o rompimento das disciplinas engessadas em áreas específicas do conhecimento, que não estabelecem relação interdependente com o mundo.

A partir dessa reflexão, se questiona: qual a maior dificuldade das instituições em introduzirem na prática conteúdos que sejam construídos em consonância com a realidade do discente?

Nessa perspectiva, David Ausubel (2002 apud Moreira, 2006) explana que introduzir um conhecimento, sem considerar o que a criança já conhece, é insatisfatório, pois ela não terá base para se ancorar.

Em consonância com o autor, Freire (1996) argumenta que para a construção de uma aprendizagem significativa, o aluno não pode ser considerado uma "tábula rasa", desprovido dos conhecimentos acumulados ao decorrer da vida, sendo fundamental que se contemple as experiências, os valores e a realidade social de cada educando.

Jorge, Carpio e Xavier ao discursarem sobre a Aprendizagem Significativa, afirmam que:

À medida que o indivíduo se torna autônomo, a partir de sua estrutura de conhecimentos, ele é capaz de captar e apreender outras circunstâncias de conhecimentos assemelhados e de se apropriar da informação, transformando-a em conhecimento. (JORGE; CARPIO; XAVIER, 2020, p.2). 
Desta forma, pretende-se elaborar posições e conclusões sobre o tema proposto, a partir da necessidade do sistema educacional em reformular a suas práticas, visando alcançar melhores resultados no campo do ensino, utilizando os temas contemporâneos transversais, através de atividades que contemplem saberes significativos e estimulem o aluno a se sentir parte da proposta pedagógica e do meio que o cerca, facilitando, assim uma leitura mais aguçada do mundo.

A partir desse panorama, busca-se refletir acerca da prática pedagógica e da existência de um currículo comprometido com a formação de cidadãos socialmente responsáveis e aptos para atuar de forma crítica na sociedade em que vivem, de maneira que a transversalidade figure como eixo unificador que permeia as diferentes disciplinas. Também, objetiva-se o diálogo referente a aplicação dos Temas Contemporâneos Transversais como ativadores dos saberes subsunçores, propostos por David Ausubel (2002 apud Moreira, 2006) em sua teoria, a fim de viabilizar o aprendizado de novos conteúdos sustentados nos anteriores.

\section{PERCURSO METODOLÓGICO}

Para consecução dos objetivos expostos, foi realizada pesquisa bibliográfica e documental; análise da pesquisa com o grupo de estudos, através de debates que viabilizaram a construção colaborativa de conhecimentos sobre os temas contemporâneos transversais, propostos pela Base Nacional Curricular Comum de 2017; familiarizando-se com os principais conceitos discutidos durante as reflexões sobre a pesquisa no campo educacional, que coadunam com a Teoria da Aprendizagem Significativa, desenvolvida pelo psicólogo David Paul Ausubel, no processo de ensino e aprendizagem.

Este estudo foi desenvolvido em duas etapas: uma revisão teórico-conceitual, por referenciais bibliográficos, utilizando bases de indexação de dados do portal de Periódicos Capes e uma pesquisa exploratória-descritiva, sobre o tema, com mestrandos do PROFEPT, mediante o desenvolvimento de atividades da disciplina Teorias e Práticas do Ensino e Aprendizagem.

Na primeira etapa foi investigado como o ensino por meio da Teoria da Aprendizagem Significativa, desenvolvida pelo psicólogo David Paul Ausubel está relacionado com os Temas Contemporâneos Transversais (TCT's) e na segunda etapa foram realizados debates com intuito de aprofundar algumas questões que emergiram na primeira etapa. Ambas com o 
intuito de verificar a importância de se considerar os conhecimentos subsunçores dos discentes ao propor práticas pedagógicas comprometidas com a formação de cidadãos críticos e participativos da ação social.

\section{RESULTADOS E DISCUSSÃO}

As disciplinas escolares, fundadas na compartimentalização de saberes, ilustram a existência de um sistema educacional permeado pela fragmentação curricular. Conforme Severino (2012, p.38-39),

(...) é possível identificar como vinculada a essa fragmentação generalizada, a desarticulação da vida da escola com a vida da comunidade a que serve, do pedagógico com o político, do microssocial com o macrossocial. Tudo se passa como se se tratasse de dois universos autônomos, desenvolvendo-se paralelamente, intercomunicando-se apenas de maneira formal, mecânica, burocrática, como se entre escola e comunidade não houvesse um cordão umbilical. (SEVERINO, 2012, p.38-39).

Santomé (1998), elucida que os discentes apresentam dificuldades no aprendizado, por terem como realidade o currículo escolar desarticulado por diversas matérias que não dialogam. Nesse sentido, Freire (1996) também evidencia um modelo de educação ao qual ele denominou de "bancária", que consiste em ter o aluno como um depósito de informações e encobrir a sua autonomia perante os conteúdos escolares, com isso o discente se torna um simples espectador do seu próprio processo de ensino.

Em contraposição a esse saber cartesiano e almejando uma educação comprometida com a formação integral do indivíduo, surgem instrumentos, como a interdisciplinaridade, a transdisciplinaridade e a transversalidade, que auxiliam a diminuição do abismo existente entre o que se ambiciona para a educação e o que ocorre na prática das escolas brasileiras.

A transdisciplinaridade tem sua origem no teorema de Gödel, autor que, em 1931, propôs distinguir vários níveis de realidade, nas palavras de Akiko Santos (apud Mello, 1999), surgindo como uma forma de aproximar o aluno de temas essenciais a sua formação emancipada, podendo ser aplicada aos diversos níveis e modalidades de ensino. Seu emprego torna-se ainda mais importante na Educação Profissional Tecnológica (EPT), consoante a formação integral do indivíduo, por romper paradigmas oriundos da dualidade educacional histórica que esse segmento traz, por consequência, da divisão de classes. 
A utilização dos, atualmente, denominados Temas Contemporâneos Transversais (TCTs) pode nortear ações escolares e auxiliar a superação da compartimentalização curricular.

A Base Nacional Comum Curricular de 2017, documento responsável por nortear os currículos e as propostas pedagógicas das escolas da rede pública e privada para toda a Educação Básica, de natureza normativa, integra a política Nacional para Educação Básica. De acordo com esse documento, compete aos sistemas e as redes de ensino absorver ao currículo (preferencialmente de maneira transversal e integradora) os temas contemporâneos que exercem influência na existência humana, em suas diferentes escalas (BRASIL, 2017).

No documento intitulado "Temas Contemporâneos Transversais na BNCC. Contextos Históricos e Pressupostos Pedagógicos", os TCT's são evidenciados como uma possibilidade de interligar componentes curriculares de maneira integrada, possibilitando a construção de conexões do aluno com a sua realidade. Por intermédio de seu estudo é possível proporcionar ao educando a formação para a cidadania, para o trabalho e para a democracia. Sua divisão é feita em seis macroáreas temáticas e quinze temas contemporâneos (BRASIL, 2018b):

Figura 1 - Macroáreas temáticas dos TCTs.

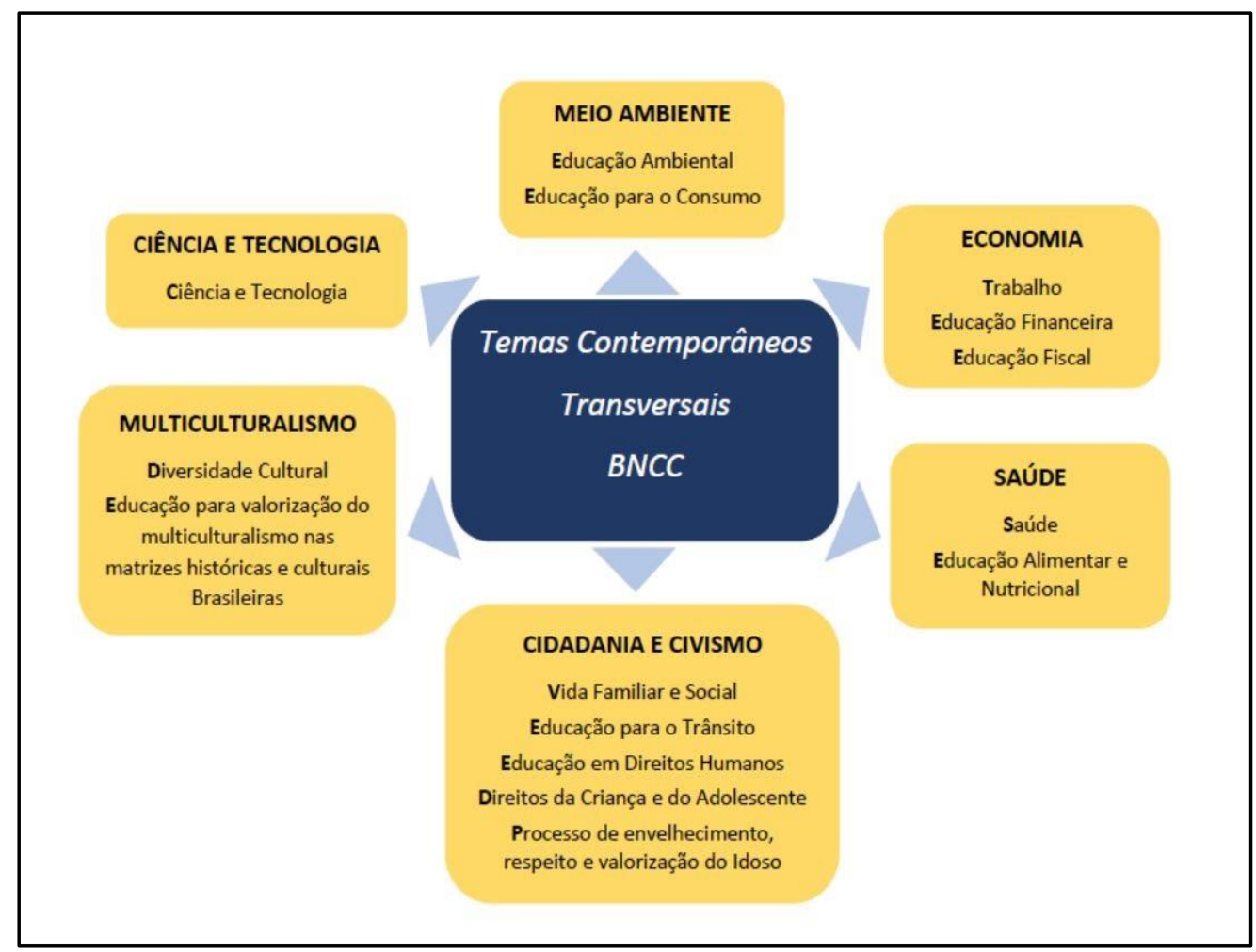

Fonte: BRASIL, 2018a, p. 07. 
Por serem contemplados na BNCC (2017) como adesão obrigatória no âmbito educacional, os TCT's obtiveram intensa relevância na elaboração dos currículos escolares. Para toda nova concepção pedagógica ter sua aplicabilidade eficaz na prática, é primordial a ancoragem em estruturas teóricas para que toda o processo de construção do conhecimento seja significativo.

Essa concepção curricular se coaduna com os Parâmetros Curriculares Nacionais (PCN), visto que, as disciplinas tradicionais formam o eixo estruturador, e em seu torno circulam, transversalmente, os temas do cotidiano da sociedade.

A BNCC expõe ainda sugestões metodológicas para os trabalhos com os Temas Contemporâneos Transversais, com o objetivo de incentivar a elaboração de estratégias de atuação que possibilitem ao aluno ressignificar a informação e integrá-la ao seu repertório de saberes. Marinho, Silva e Ferreira (2015), elaboraram o quadro abaixo em que se pode verificar três formas distintas de articulação dos conteúdos tradicionais com os transversais:

Quadro 1 - Relação entre os conteúdos tradicionais e os transversais

\begin{tabular}{|l|l|l|}
\hline \multicolumn{1}{|c|}{ Primeira forma } & \multicolumn{1}{c|}{ Segunda forma } & \multicolumn{1}{c|}{ Terceira forma } \\
\hline $\begin{array}{l}\text { - Relação intrínseca. } \\
\text { - Não existem distinções } \\
\text { claras entre conteúdos } \\
\text { tradicionais e } \\
\text { transversais. }\end{array}$ & $\begin{array}{l}\text { - Relação pontual. } \\
\text { - Viabilizada por meio de } \\
\text { módulos ou projetos } \\
\text { específicos. }\end{array}$ & $\begin{array}{l}\text { - Relação de integração } \\
\text { interdisciplinar entre conteúdos } \\
\text { tradicionais e os temas } \\
\text { transversais. }\end{array}$ \\
\hline $\begin{array}{l}\text { Ex.: Um professor de } \\
\text { matemática jamais } \\
\text { imagina o conteúdo } \\
\text { que trabalha } \\
\text { desvinculado da } \\
\text { construção da } \\
\text { democracia e da } \\
\text { cidadania. }\end{array}$ & $\begin{array}{l}\text { Ex.: Em determinados } \\
\text { momentos o professor de } \\
\text { matemática deixaria de } \\
\text { trabalhar somente a sua } \\
\text { disciplina e incorporaria } \\
\text { algum tema transversal em } \\
\text { suas aulas. }\end{array}$ & $\begin{array}{l}\text { Ex.: O professor de matemática } \\
\text { necessita integrar o conteúdo } \\
\text { específico de sua área não só aos } \\
\text { temas transversais, mas também } \\
\text { aos demais conteúdos } \\
\text { curriculares, como língua } \\
\text { portuguesa e ciências. }\end{array}$ \\
\hline
\end{tabular}

Fonte: MARINHO, SILVA e FERREIRA (2015, p. 433) 
Os TCT's também auxiliam a abordagem das metas, para erradicar a pobreza e promover vida digna para todos, dentro dos limites do planeta, e dos Objetivos de Desenvolvimento Sustentável (ODS) da Agenda 2030 (plano de ação dos 193 Estadosmembros da ONU, entre eles o Brasil, que se comprometeram a tomar medidas ousadas e transformadoras para promover o desenvolvimento sustentável até 2030).

Figura 2 - Os Objetivos de Desenvolvimento Sustentável da Agenda 2030

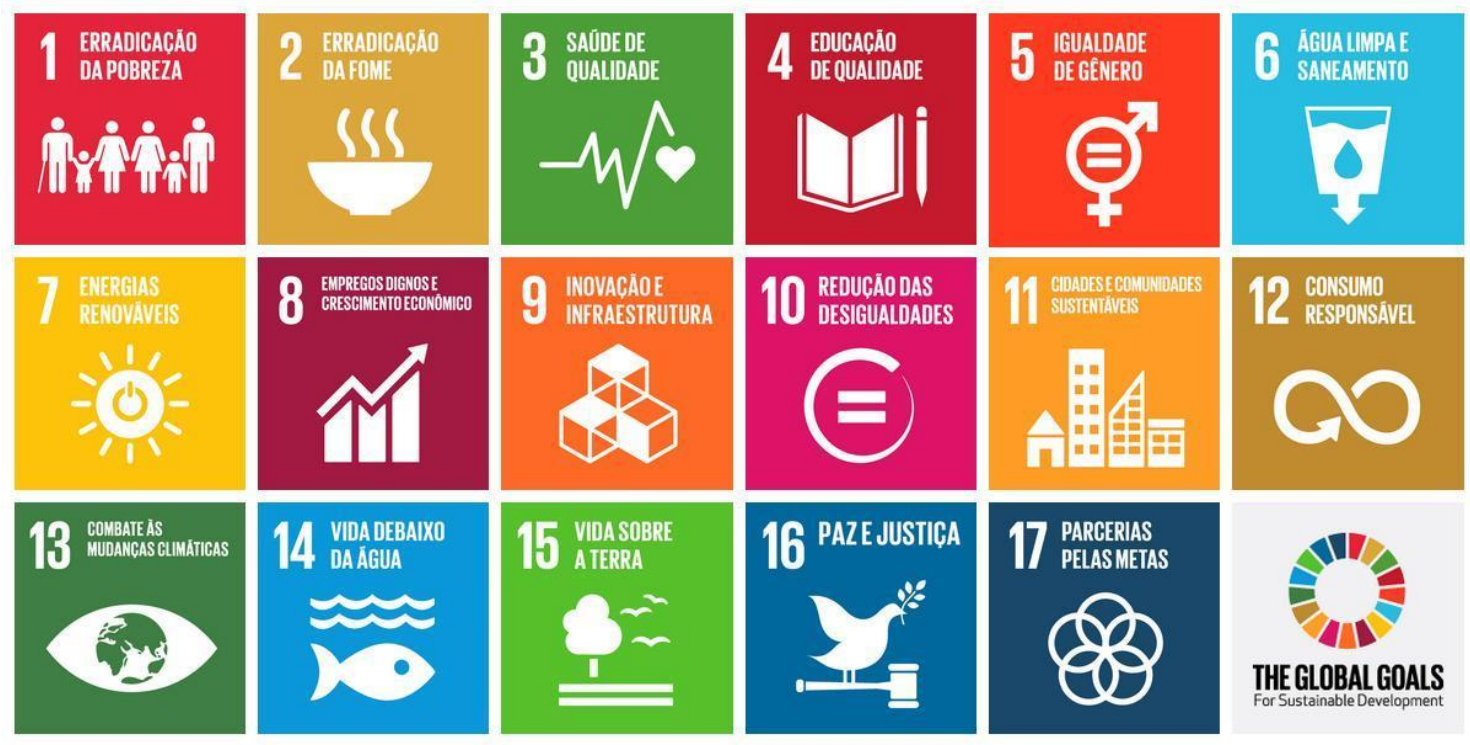

Fonte: CENTRO DE INFORMAÇÃO DAS NAÇÕES UNIDAS (2015)

Uma possibilidade de construir os TCT's no processo educativo, se faz através da aplicabilidade da Teoria da Aprendizagem Significativa de David Ausubel. O princípio básico da concepção do teórico, consiste na relação entre conhecimentos prévios e os novos conhecimentos para construir a então aprendizagem significativa. $\mathrm{O}$ referido autor denomina os saberes precedentes do indivíduo de conceitos subsunçores e afirma que esses servem de base para a construção de novos saberes, nessa perspectiva. Ainda, Moreira (2006) afirma que esse processo é interativo, pois ao embasar os novos saberes, os antigos também sofrem um processo de ressignificação, adquirindo mais estabilidade e alicerçando os novos conhecimentos que surgirem.

Desta forma, através das potencialidades da Teoria da Aprendizagem Significativa, é possível integralizar os TCT's nas instituições escolares empregando-os para ativar os 
conhecimentos subsunçores dos educandos, a fim de viabilizar a formação de novos aprendizados por meio de saberes contextualizados, como enfatizado pela BNCC (2017), sendo excelentes âncoras para oportunizar o processo de ensino e aprendizagem embasados nessa concepção.

Esse novo panorama da educação, contribui para que o processo de ensino se consolide através de condutas que enalteça o protagonismo do aluno e faça do docente, um profissional mediador de todos as descobertas que surgirem, estabelecendo como o educando uma relação horizontal para que juntos busquem novos saberes.

Educador e educandos se arquivam na medida em que, nesta distorcida visão da educação, não há criatividade, não há transformação, não há saber. Só existe saber na invenção, na reinvenção, na busca inquieta, impaciente, permanente, que os homens fazem no mundo, com o mundo e com os outros. (Freire, 1987, p. 58).

Nessa visão, o trecho da obra de Freire (1987) coaduna com o ativismo e a criticidade do educando e do educador em sala de aula, pois demonstra que só existirá eficácia no aprendizado, se ambos trabalharem em prol da transformação da realidade e da ressignificação do conhecimento.

Moreira (2011) reflete que uma das premissas da teoria da aprendizagem significativa, se pauta em uma observação minuciosa aos conteúdos que serão construídos no âmbito educacional, objetivando sinalizar quais são os saberes que deverão ser explorados, a fim de não projetar, no processo de ensino, informações desconexas e sem representatividade aos discentes, impossibilitando o seu avanço cognitivo.

Um exemplo prático da aplicação dos TCT's para ativar conhecimentos subsunçores na EPT e em outros segmentos, podem ser detectados em aulas de matemática, quando antes de introduzir o conteúdo referente a juros, o professor através do TCT "Educação financeira" contido na macroárea de economia, consegue ativar conhecimentos prévios dos educandos, usando como base as despesas do cotidiano, diagnosticando que tipo de experiência com a temática os alunos dispõem e apresentando dados verídicos sobre o sistema financeiro do país, para que então, a temática não transcorra apenas como teoria abstrata e o educando possa estabelecer relações do que está sendo construído e o seu meio social, possibilitando caminhos para uma aprendizagem significativa. 
Identifica-se outro exemplo prático na Macroárea referente a saúde. O docente antes de introduzir o conteúdo referente a informação nutricional dos alimentos, consegue se ancorar no tema "Educação Alimentar e Nutricional" para ativar conhecimentos prévios, como por exemplo a possível ingestão de alimentos com ou sem glúten, as características de alimentos que possuem lactose, entre outros tópicos que facilitam a captação dos conhecimentos subsunçores, por terem grande notoriedade na sociedade através dos veículos de comunicação.

Com a macroárea referente ao "Meio Ambiente" é possível fazer menção a rios próximos à comunidade escolar que estejam poluídos, para que se possa adentrar em temas como poluição ao meio ambiente e saneamento básico.

Os exemplos das práticas acima, são alguns mecanismos para a ativação dos conhecimentos prévios do aluno, a fim de conquistar e ressignificar novos saberes. É de suma importância que haja observação às peculiaridades da comunidade escolar para a escolha dos TCT's.

\section{CONSIDERAÇÕES FINAIS}

Segundo a BNCC os currículos e as propostas pedagógicas devem abordar temas contemporâneos que afetam a vida humana em escala local, regional e global, preferencialmente de forma transversal e integradora (BRASIL, 2017, p. 19).

Desta forma, os Temas Contemporâneos Transversais se apresentam como forma de transformação do currículo, de caráter integrador, que demandam além de soluções pedagógicas, o verdadeiro compromisso com a transformação da educação.

Por conseguinte, sua articulação com a Teoria da Aprendizagem Significativa pode transformar-se em paradigmas que norteiam as ações educacionais brasileiras, a fim de despertar no discente a busca por conhecimentos prévios e por conseguinte construir novas estruturas de saberes que ao permear por esse processo se tornam mais estáveis.

\section{REFERÊNCIAS}

BRASIL. Ministério da Educação. Base Nacional Comum Curricular. MEC, 2017. Brasília, DF, 2017. Disponível em: http://basenacionalcomum.mec.gov.br/images/BNCC EI EF 110518 versaofinal site.pdf. Acesso em 15 de mai. 2020. 
BRASIL. Ministério da Educação. Temas Contemporâneos Transversais na BNCC. Propostas de Práticas de Implementação. MEC, Brasília, DF, 2018 (2018a). 1 Figura. Disponível em http://basenacionalcomum.mec.gov.br/images/implementacao/guia_pratico_temas_contempor aneos.pdf. Acesso em 15 de mai. 2020.

BRASIL. Ministério da Educação. Temas Contemporâneos Transversais na BNCC. Contexto Histórico e Pressupostos Pedagógicos. MEC, Brasília, DF, 2018 (2018b). Disponível em:

http://basenacionalcomum.mec.gov.br/images/implementacao/contextualizacao_temas_conte mporaneos.pdf. Acesso em 15 de mai. 2020.

CENTRO DE INFORMAÇÃO DAS NAÇÕES UNIDAS (Rio de Janeiro, RJ). Agenda 2030. 2015. 2 Figura. Disponível em: https://nacoesunidas.org/pos2015/agenda2030/. Acesso em: 10 ago. 2020.

CORREIA, D. A.; MALDANER, J. J.; CAVAlCANTE, R. P.; SOUSA, W. A. de. A Educação Profissional Tecnológica na Base Nacional Comum Curricular: concepções e contradições. Revista Prática Docente, [S. l.], v. 5, n. 1, p. 563-581, 2020. Disponível em: http://periodicos.cfs.ifmt.edu.br/periodicos/index.php/rpd/article/view/618. Acesso em: 19 abr. 2021.

FERREIRA, Júlia; AZEVEDO, Rosa; STEFANUTO, Vanderlei. Contribuições de Assistentes Sociais para a Formação Humana Integral de Estudantes da EPTNM do IFAM. Educação Profissional e Tecnológica em Revista, [S.1.]. v. 2, $\mathrm{n}^{\circ}$ 2, 2018. p.133-151. Disponível em: https://ojs.ifes.edu.br/index.php/ept/article/view/430/377. Acesso em: 19 abr. 2021.

FREIRE, Paulo. Pedagogia da autonomia: saberes necessários à prática educativa. 31ed. São Paulo: Paz e Terra, 1996.

FREIRE, Paulo. Pedagogia do oprimido. $17^{\text {a }}$ ed. Rio de Janeiro: Paz e Terra, 1987.

JORGE, Maurício Lourenço; CARPIO, Ricardo Carrasco; XAVIER, Gláucia do Carmo. APRENDIZAGEM SIGNIFICATIVA: PROPOSTA DE UM KIT DIDÁTICO PARA PROCESSOS DE FABRICAÇÃO E MONTAGEM DE COMPONENTES MECÂNICOS. Revista Brasileira da Educação Profissional e Tecnológica, [S.1.], v. 2, n. 19, p. e9836, maio 2020. ISSN 2447-1801. Disponível em:

<http://www2.ifrn.edu.br/ojs/index.php/RBEPT/article/view/9836>. Acesso em: 19 abr. 2021.

MARINHO, Julio Cesar Bresolin; SILVA, João Alberto da; FERREIRA, Maira. A educação em saúde como proposta transversal: analisando os Parâmetros Curriculares Nacionais e algumas concepções docentes. História, Ciências, Saúde - Manguinhos, Rio de Janeiro, v.22, n.2, abr.-jun. 2015, p.429-443. Disponível em:

http://www.scielo.br/pdf/hcsm/v22n2/0104-5970-hcsm-2014005000025.pdf. Acesso em: 15 de mai. 2020. 
MOREIRA, M.A. A teoria de aprendizagem significativa e sua implementação em sala de aula. Brasília: Editora da UnB, 2006. p. 13-42

MOREIRA, M.A. A aprendizagem significativa: Um conceito Subjacente 2011, p.153156.

NAÇÕES UNIDAS NO BRASIL - ONU BR. A Agenda 2030. Disponível em: https://nacoesunidas.org/pos2015/agenda2030/ . Acesso em: 15 de mai. 2020.

SANTOMÉ, Jurgo Torres. Globalização e interdisciplinaridade: o currículo integrado. Trad. Cláudia Schilling. Porto Alegre: Editora Artes Médicas Sul Ltda., 1998.

SANTOS, Akiko. Complexidade e transdisciplinaridade em educação: cinco princípios para resgatar o elo perdido. Rev. Bras. Educ. [online]. 2008, vol.13, n.37, pp.71-83. Disponível em: http://www.scielo.br/pdf/rbedu/v13n37/07.pdf. Acesso em: 11 de mai. 2020.

SEVERINO, A.J. O conhecimento pedagógico e a interdisciplinaridade: O saber como intencionalização da prática. In: Fazenda, I.C.A. (Org.). Didática e interdisciplinaridade. $17^{a}$ ed. Campinas, SP: Papirus, 2012. Coleção Práxis. 